\title{
Northern midlatitude stratospheric ozone dilution in spring modeled with simulated mixing
}

\author{
Bjørn M. Knudsen \\ Danish Meteorological Institute, Copenhagen, Denmark \\ Jens-Uwe Grooß \\ Forschungszentrum Jülich, Institute for Stratospheric Chemistry , Jülich, Germany
}

\begin{abstract}
Measurements have shown a substantial decrease in Northern midlatitude ozone, which has only partially been explained by chemical models. The large ozone depletions determined for the Arctic vortex in recent winters will ultimately spread out and dilute the midlatitudes and thus contribute to the observed decrease. Here we have followed the ozone-depleted air inside the Arctic vortex in 1995 and 1997 during April and May with high-resolution reverse domain-filling (RDF) trajectory calculations. The resulting average midlatitude $\left(30^{\circ}-60^{\circ} \mathrm{N}\right)$ stratospheric ozone dilution in May is $2.9 \%$ and 2.6\% of the 1979 column ozone in 1995 and 1997, respectively, or about $40 \%$ of the observed depletion. Nearly realistic mixing was introduced by a regridding procedure between successive 7-day long RDF calculations. Low-resolution grid point models give too much mixing, causing an overestimate of the calculated dilution. A recovery of about $12 \%$ of the midlatitude dilution in May 1997 is calculated with a photochemical box model, but is not included in the number given above.
\end{abstract}

\section{Introduction}

Satellite measurements have shown a significant decline in ozone at midlatitudes [World Meteorological Organization (WMO), 1999]. Using two-dimensional (2-D) models it has in the past been argued that in-situ chemistry could explain the decline [Solomon et al., 1996], but in the later years 3-D model studies have shown that this is not the case. Chipperfield [1999] used a 3-D chemical transport model (CTM) to show that heterogeneous chemistry on polar stratospheric clouds and cold aerosols makes a substantial contribution to the ozone decline at midlatitudes. Knudsen et al. [1998a] showed evidence that dilution with ozone-depleted air from the Arctic vortex is an important factor in the depletion in spring. Dilution is defined here as ozone depletion resulting from both irreversible and reversible transport of ozone-depleted air from the vortex. The reversible transport (without mixing) might not unequivocally be included in the definition, but if preferred the word "dilution" could simply be replaced by "depletion". Predominantly in April and later after the final breakup of the Arctic vortex, the dilution in midlatitudes with ozone depleted air from the vortex becomes important. The dilution before the final breakup is usually limited because the vortex erosion usually is quite weak [McIntyre, 1995;Waugh et al., 1994]. Knudsen et al. [1998a] found a substantial dilution in May 1997 using height-resolved estimates of the vortex ozone depletions [Knudsen et al., 1998b] and high-resolution reverse domain-filling (RDF) trajectory calculations. In this paper the calculations of Knudsen et al. [1998a] are extended to 1995 and are improved with nearly realistic mixing obtained by a regridding procedure. For the high-resolution calculations used here,

Copyright 2000 by the American Geophysical Union.

Paper number 1999JD901076.

0148-0227/00/1999JD901076\$09.00 the inclusion of mixing does not have a substantial effect on the zonally averaged dilution, but it is shown that the excessive mixing in low-resolution grid point models does. Further, the photochemical recovery from the ozone depletion, which was not included by Knudsen et al. [1998a], is calculated.

The paper is organized in the following way: Section 2 describes the RDF calculations and the derivation of the dilution. Section 3 presents the resulting dilution. In section 4 the mixing properties of the regridding procedure are analyzed, while section 5 studies the photochemical recovery of ozone. Finally, section 6 offers some conclusions.

\section{RDF Calculations}

The RDF calculations are described by Knudsen et al. [1998a,b], but the description is repeated here. The calculations use 6 hourly European Centre for Medium-Range Weather Forecasts (ECMWF) analyses in a $1.5^{\circ}$ latitude-longitude grid. The RDF calculations are performed in an equal-area grid with a grid distance of $1^{\circ}$ by latitude $(\sim 111 \mathrm{~km})$, and the number of longitudes at each latitude is given by the integer closest to $360 \cos (\phi)$, where $\phi$ is the latitude. The longitude $0^{\circ} \mathrm{E}$ is always included. The calculations end on the $350,375,400,425,450,475,500,525$, and $550 \mathrm{~K}$ potential temperature $(\theta)$ levels. The calculations are three-dimensional since $\theta$ in each time step is changed by the diabatic heating. The heating rate calculations are done with the ECMWF radiation scheme [Morcrette, 1991] and they are described by Knudsen et al. [1998b] except that the Committee on Space Programs and Research (COSPAR) International Reference Atmosphere (CIRA) ozone climatology [Keating et al., 1990] and Stratospheric Aerosol and Gas Experiment (SAGE) $\mathrm{H}_{2} \mathrm{O}$ [Chiou et al., 1997] have been used here.

We study the dilution in spring 1995 and 1997, because only for these years have height-resolved vortex ozone depletions been quantified [Rex et al., 1999; Knudsen et al., 1998b]. The vortex 
depletions and definitions of the vortex edge were taken directly from these studies. Rex et al. [1999] matched different ozonesondes with air parcel trajectories to determine the ozone depletion rate. They found an integrated vortex ozone depletion from 370 to $600 \mathrm{~K}$ of 127 Dobson units (DU) (29\% of the total column) between January 1 and March 30, 1995. Knudsen et al. [1998b] averaged vortex ozone mixing ratios from ozonesondes corrected for diabatic cooling and transport across the edge of the vortex and found an average ozone depletion inside the vortex in the potential temperature region $350-550 \mathrm{~K}$ of $92 \mathrm{DU}(21 \%)$ from January 1 to April 11, 1997.

The subvortex depletion below $400 \mathrm{~K}$ derived for 1997 by Knudsen et al. [1998b] is somewhat questionable due to the fact that the quasi-isentropic ozone transport in this region becomes more important and at the same time more uncertain. On April 11,1997 , it amounts to $28 \%$ of the total vortex depletion and contributes approximately the same fraction to the midlatitude dilution. On March 30,1995, 42\% of the vortex depletion is below $400 \mathrm{~K}$. However, the method used by Rex et al. [1999] works also below the vortex, as the given error bars indicate. The depletions in these studies agree well with depletions of $32 \pm 4 \%$ and $24 \%$ in 1995 and 1997 , respectively, determined by Goutail et al. [1998,1999]. Note, however, that all the above mentioned methods of calculating the vortex depletion are dependent on calculated heating rates, which are relatively uncertain in the lower stratosphere [Olaguer et al., 1992].

The accumulated loss in the ozone mixing ratio on March 30 , 1995, and April 11, 1997, is denoted $X_{\text {dep. }}$. It is assumed to be advected unchanged along the trajectories. Since photochemistry is treated separately, this is equivalent to advecting both observed and undepleted (= observed + depleted) ozone and taking the difference. The integrated column ozone dilution, $\Omega_{d l}$, is given in DU from equation (1) of Knudsen et al. [1998a]:

$$
\Omega_{d l l}=-0.788 \int_{p(350 K)}^{p(550 K)} \mathrm{X}_{d c p} d p
$$

when $X_{d c p}$ is given in ppmv and $p$ in hPa. In 1995 the upper limit was kept at $550 \mathrm{~K}$ throughout the calculation because Rex et al. [1999] determined the depletion up to $600 \mathrm{~K}$. The air at $550 \mathrm{~K}$ on May 31,1995 , originated from approximately $580 \mathrm{~K}$ on March 30. The depletion between 550 and $580 \mathrm{~K}$ on March 30, 1995, constitutes less than $1 \%$ of the total depletion, and the depletion above $512.5 \mathrm{~K}$ is in fact not statistically significant and is mostly natural (not due to polar stratospheric clouds (PSCs)) [Rex et al., 1999]. In 1995 the lower limit of the depletion was at $370 \mathrm{~K}$ initially, but by May $31,4 \%$ of the total depletion (in kilograms) had descended below $350 \mathrm{~K}$ and was discarded. A further $3 \%$ of the total depletion had entered the troposphere (potential vorticity (PV) $\left.<2 \times 10^{-6} \mathrm{~K} \mathrm{~m}^{2} \mathrm{~kg}^{-1} \mathrm{~s}^{-1}\right)$ ) and was also discarded. By May 18 , $1995,2 \%$ of the total depletion had entered the troposphere, and $0 \%$ had descended below $350 \mathrm{~K}$. For the May average dilution a total of $3 \%$ has been discarded, which is negligible.

In 1997 the depletion was only available up to $550 \mathrm{~K}$. Therefore the upper limit of the integral descends diabatically together with the ambient air from $550 \mathrm{~K}$ on April 11 to $541 \mathrm{~K}$ on average by May 30. In 1997 none of the depletion had entered the troposphere by May 30 .

The RDF calculations are split up into successive 7-day calculations, except that the last calculation ending on May 31, 1995, is only 6 days long. After each 7-day period the starting (in time) point of the next RDF calculation is given a mixing ratio of depleted ozone which is bilinearly interpolated between the four closest endpoints of the previous calculation. This regridding introduces a nearly realistic mixing (see below). The vertical interpolation of the mixing ratios is linear in $\theta$ because the trajectory endpoints are given on isentropic levels. Such a vertical interpolation might not generally be optimal, but with only $25 \mathrm{~K}$ spacing in $\theta$, the interpolation method hardly matters.

On May 30, 1997, the total advected ozone depletion is a factor of 1.17 larger than on April 11, 1997. This is due to inconsistencies between the RDF advection and the analysis mass field or to errors in the diabatic heating calculations, which are quite uncertain in the lower stratosphere. All results shown here are corrected for these factors. Two tests of the effect of the initializations of the heating rate calculations on this factor were made: Without inclusion of clouds in the radiative calculations, the factor increases to 1.19. Potentially more realistic ozone was introduced by using the vortex-averaged ozone mixing ratios from ozonesondes during the period April 1-11, 1997 [Knudsen et al., 1998b]. The background for applying these for 49 days and over the whole Northern Hemisphere is that the depleted air mostly remains inside the vortex remnants. Since the diabatic heating and the photochemical recovery are small, the PV- $\theta$ mapped vortex profile is reasonably valid throughout the calculation. In 1997 the use of PV- $\theta$ mapped ozone did not have any significant impact on the total advected ozone depletion by May 30, 1997. The reason for this is that in 1997 the mid-latitude ozone was approximately equal in the two calculations.

In 1995 the total advected ozone depletion is up to a factor of 1.28 larger during the 62-day calculation than on March 30 , 1995. In 1995, cloud information on each model level was not available before April 4, and the calculations presented here use clear-sky heating rates. An initial vortex ozone profile is taken from an ozonesonde on March 30, 1995, launched from Ny Ålesund $\left(79^{\circ} \mathrm{N}, 12^{\circ} \mathrm{E}\right)$ when the station was well inside the vortex. If clouds are included in the calculations after April 6 together with this vortex ozone profile, then the total advected ozone depletion during the full 62 day calculation is less than a factor of 1.19 larger than initially. Nevertheless, these calculations did not make any significant changes in the midlatitude dilutions and were not used in this study (except in the photochemical calculations) because of their potentially large errors.

It should be noted that circulation changes due to the dilution have not been taken into account in this study. However, Prather et al. [1990] found that the recovery from the Antarctic ozone hole due to increased transport from the tropics and reduced transport into the troposphere is only a minor fraction of the photochemical recovery during spring.

The breakup of the vortex is a period that is probably particularly poorly analyzed due to the rapid dynamical development. Therefore Knudsen et al. [1998a] calculated the isentropic dilution using both ECMWF and U.K. Meteorological Office (UKMO) analyses. When correction is made for the factor the total depletion has increased during the 28 days of calculation (this was not done by Knudsen et al. [1998a]) the UKMO midlatitude dilution is 0.97 times the ECMWF dilution. However, the difference is, in fact, caused by the difference in spatial and temporal resolution of the analyses.

\section{Northern Midlatitude Dilution in 1995 and 1997}

The column ozone dilution, $\Omega_{d l l}$, on May 25,1997 , is shown in Plate 1. This day was chosen in order to compare with the results of Knudsen et al. [1998a] without regridding. Note, however, that the scale is different and that the results of Knudsen et al. [1998a] are not corrected for the factor of 1.15 by which the 


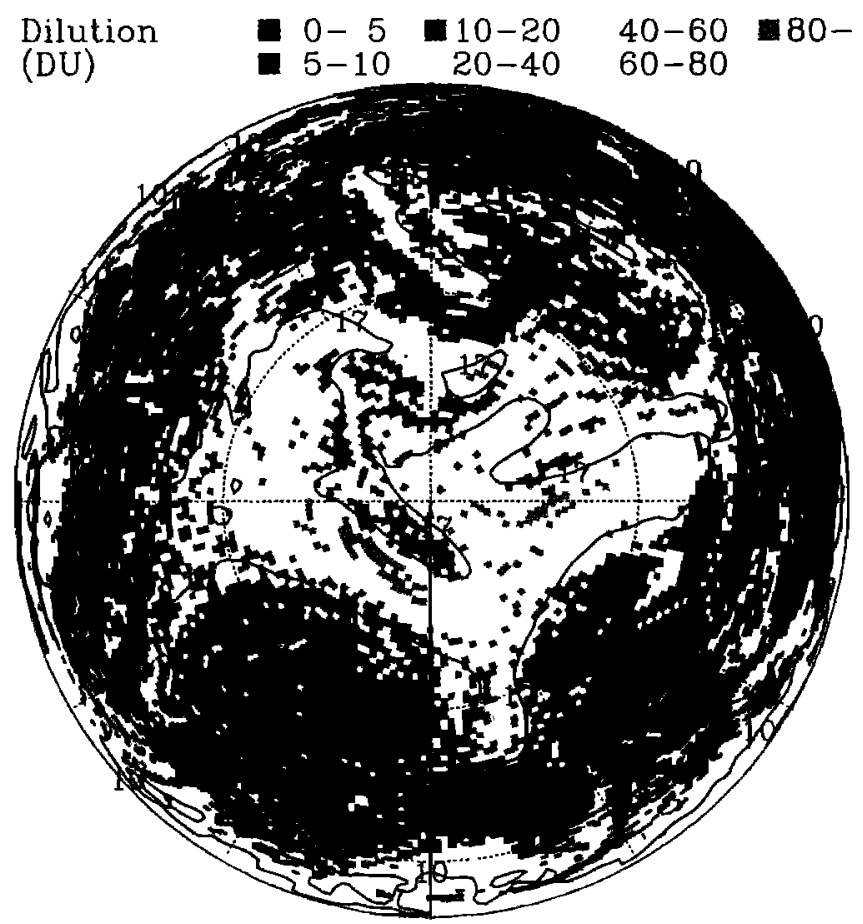

Plate 1. Northern Hemispheric dilution on May 25, 1997. Contours of 10 and $17 \times 10^{-6} \mathrm{~K} \mathrm{~m}^{2} \mathrm{~kg}^{-1} \mathrm{~s}^{-1}$ potential vorticity (PV) at $435 \mathrm{~K}$ are overlaid to mark the tropical edge and vortex remnants, respectively. Only points with a nonzero dilution are plotted. The projection is orthographic with latitude circles at $0^{\circ}$, $30^{\circ}$, and $60^{\circ} \mathrm{N}$.

advected total depletion had increased relative to the initial depletion in their calculation. As expected, the mixing introduced by the regridding (see below) causes the dilution to be much more smeared out. PV contours of 10 and $17 \times 10^{-6} \mathrm{~K} \mathrm{~m}^{2} \mathrm{~kg}^{-1} \mathrm{~s}^{-1}$ on the $435 \mathrm{~K}$ isentropic surface are shown to mark the tropical and vortex remnant edges.

In Figure 1 the temporal development of the zonally averaged dilution in the Northern Hemisphere in spring 1995 and 1997 is shown. Figure 2 compares the average dilution in May 1995 and 1997 with the best estimate of the observed depletion from 1979 to 1997 using Total Ozone Mapping Spectrometer (TOMS) May decadal trends [WMO, 1999] multiplied by 1.8 decades. The May trends were derived through linear interpolation between the MAM (March, April, May) and JJA (June, July, August) trends $(2 / 3(\mathrm{MAM})+1 / 3(\mathrm{JJ} A))$. The total midlatitude $\left(30^{\circ}-60^{\circ} \mathrm{N}\right)$ dilution in May 1995 and 1997 is $2.9 \%$ and $2.6 \%$, respectively, or about $40 \%$ of the observed TOMS depletion in May of $6.8 \%$ of the 1979 total ozone. In April the 1995 and 1997 midlatitude dilution is $2.3 \%$ and $1.2 \%$, respectively, while the TOMS MAM depletion is $8.2 \%$. The small dilution in April 1997 is due to the exceptionally long lasting vortex that year.

\section{Mixing}

The mixing introduced by the regridding was simulated in the following way: First a straight, long, thin filament of tracer was assumed. A cross section of the filament is shown in Figure 3. The grid boxes (whose corners are endpoints of the RDF calculations) are assumed to be squares, and are assumed to be placed randomly with respect to the tracer distribution. The randomness is effectuated by moving the grid boxes in steps of $0.01^{\circ}$ (by latitude) in longitude and latitude, that is 10,000 different grids are used. The tracer concentration is bilinearly interpolated between the four closest endpoints of each grid, and the average over all grids is made. In Figure 3 the cross sections of every 25 th of the grid boxes used to determine the tracer amount at $0^{\circ}$ are shown. The simulations are performed for 44 days (i.e. from April 11 to May 25, 1997) with a regridding every seventh day (the first regridding is on the starting date and the last RDF calculation is 9 days long). The term "regridding" is, in fact, only correct backward in time, but is used for simplicity. The resulting tracer distribution is shown in Figure 3 for all six regriddings. For each regridding the simulated tracer moves further away from the initial distribution. The tracer distribution resulting from diffusion was also simulated. The diffusion equation in one dimen-
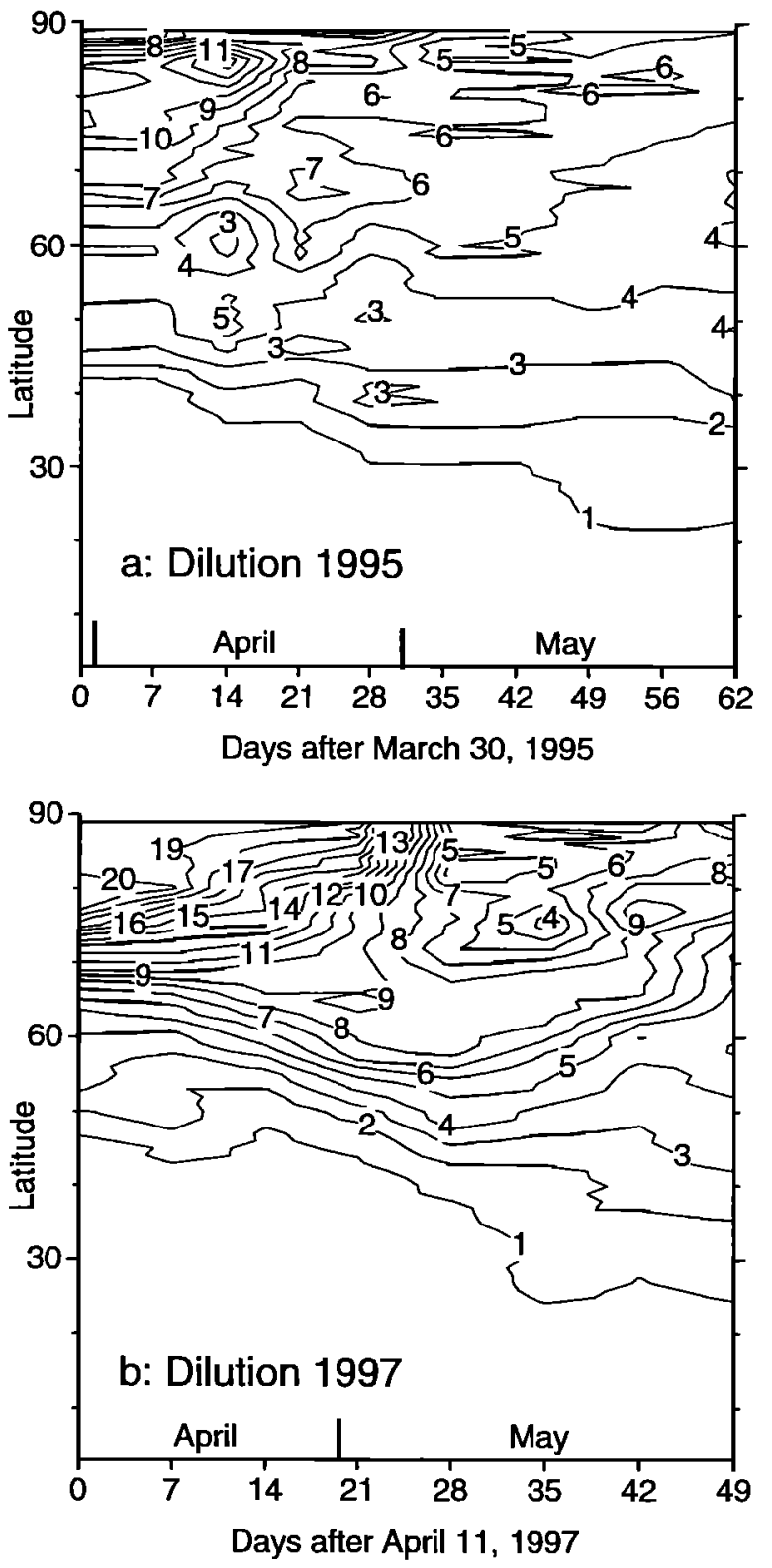

Figure 1. Temporal development of the Northern Hemispheric dilution (as a percentage of the May 1979 TOMS ozone) a) from March 30 to May 31, 1995 and b) from April 11 to May 30, 1997. 


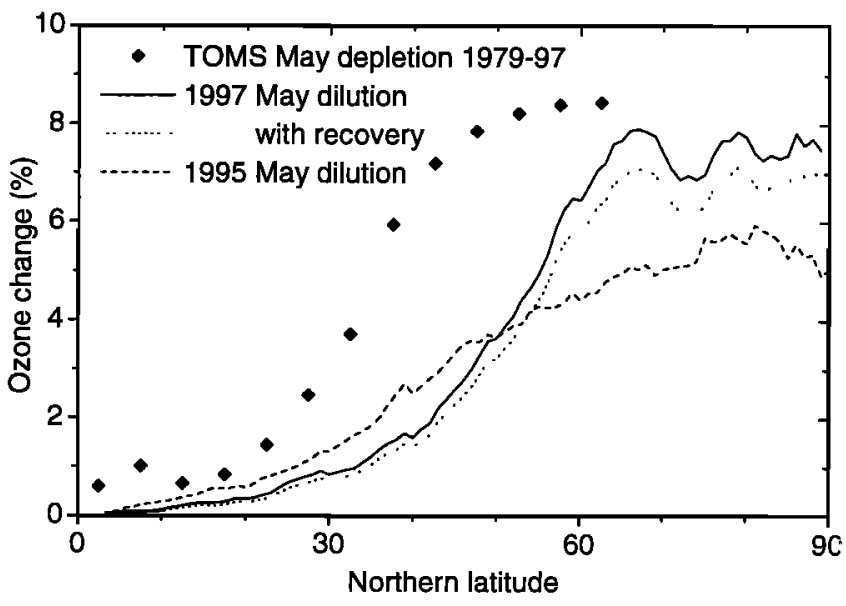

Figure 2. The May 1995 and 1997 averaged dilution compared to the May Total Ozone Mapping Spectrometer (TOMS) decadal trend 1979-1997 [WMO, 1999] multiplied by 1.8 decades. The effect of photochemical recovery is shown for the 1997 dilution as well.

sion, which is sufficient for the tracer distribution shown in Figure 3 , is given by

$$
\frac{\partial \sigma}{\partial t}=D \frac{\partial^{2} \sigma}{\partial x^{2}}
$$

where $\sigma$ is the tracer concentration and $D$ the diffusivity. In Figure 3 the resulting tracer distribution is shown after 44 days for two different (horizontal) diffusivities. Evidently, the regridding in a $1^{\circ}$ grid every seventh day is on average equivalent to diffusion with a diffusivity of $1.65 \times 10^{3} \mathrm{~m}^{2} \mathrm{~s}^{-1}$, which is close to the diffusivity of $1.0 \times 10^{3} \mathrm{~m}^{2} \mathrm{~s}^{-1}$ estimated for Northern midlatitude spring 1993 by Waugh et al. [1997] (which was quite uncertain). Using a $5^{\circ}$ grid introduces much more mixing as seen in the figure, and the diffusivity then equals $4.13 \times 10^{4} \mathrm{~m}^{2} \mathrm{~s}^{-1}$. Equation (2) shows that the diffusivity scales as the square of the grid distance and inversely with the time step. Thus a diffusivity of $1.0 \times 10^{3} \mathrm{~m}^{2}$ $\mathrm{s}^{-1}$ could be obtained by using a $0.8^{\circ}$ grid or regridding every twelfth day. Alternatively, for 44 day long calculations, the initial

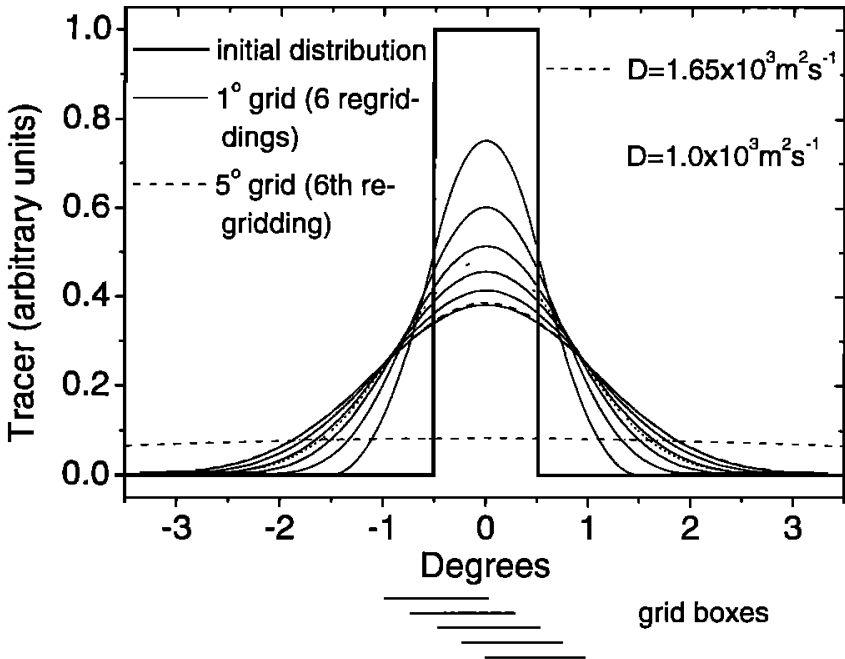

Figure 3. Development over 44 days of an initial steplike tracer concentration due to both diffusion and the regridding procedure used here.

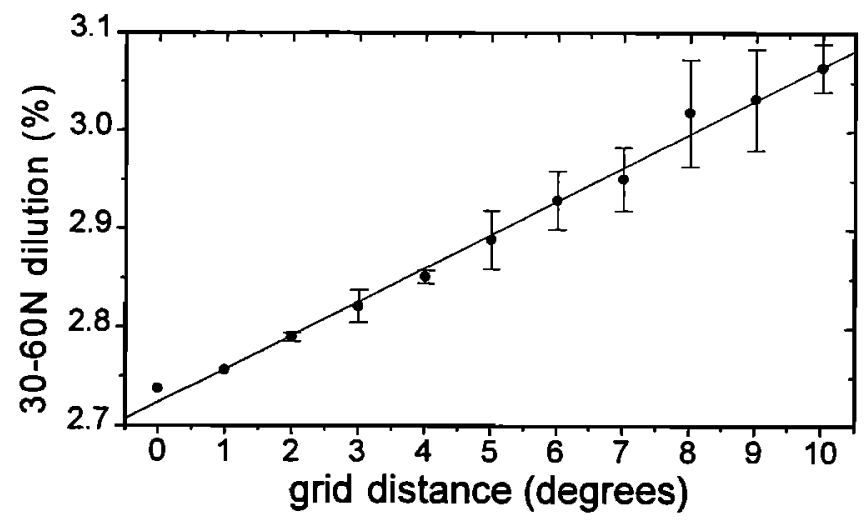

Figure 4. Calculated midlatitude dilution on May 25, 1997, as a function of the grid distance used in the reverse domain-filling (RDF) trajectory calculations.

regridding could be omitted, and regriddings every eighth or ninth day could be done. When the average of the four closest points is used instead of the bilinearly interpolated value, the diffusivity is approximately doubled. For a thick filament (i.e., the center of the filament is unchanged) the regridding procedure gave the same diffusivity. This was also the case for a circular blob of tracer, which had to be simulated two-dimensionally.

In Figure 4 the total midlatitude dilution on May 25, 1997, is shown as a function of the latitudinal grid distance. For grid distances larger than $1^{\circ}$, more than one grid is possible (e.g., for a $5^{\circ}$ grid the northernmost regular grid latitude could be $90^{\circ}, 89^{\circ}, 88^{\circ}$, $87^{\circ}$, or $86^{\circ} \mathrm{N}$ ). In the figure the mean of the results for the different grids is shown, and the error bars give the $68 \%$ confidence limits. A grid distance of $0^{\circ}$ is equivalent to RDF calculations without regridding. The linear regression line is also shown. Balluch and Haynes [1997] found a probable range of the horizontal diffusivity from $6 \times 10^{1}$ to $1 \times 10^{3} \mathrm{~m}^{2} \mathrm{~s}^{-1}$. According to Figure 4 , applying such low diffusivities would not change the calculated midlatitude dilution significantly. Grid distances of $5^{\circ}$ or $10^{\circ}$ lead to a factor of 1.05 and 1.11 larger midlatitude dilution, respectively, and Figure 5 shows that especially the dilution at lower latitudes is enhanced. Note also that Figure 5 shows that low-resolution grid point models mix away the high-latitude depletion too fast. This could contribute to the summer overesti-

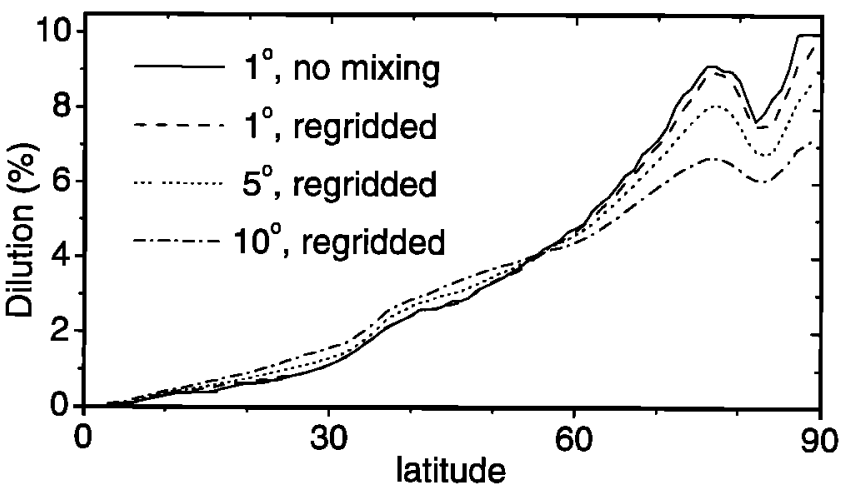

Figure 5. Dilution on May 25, 1997, as a function of latitude for single RDF calculations and for RDF calculations with regriddings every seventh day in a $1^{\circ}, 5^{\circ}$, and $10^{\circ}$ grid. The data were smoothed using a $5^{\circ}$ wide running average. 
mate of ozone in this region by current models [e.g., Chipperfield, 1999]. CTM's have more frequent regridding (in each time step), but on the other hand they often use more sophisticated interpolation methods (as for example, the Prather advection scheme [Prather, 1986]). General circulation models use artificially enhanced diffusion for stability reasons, and therefore typically have a diffusivity of $10^{6} \mathrm{~m}^{2} \mathrm{~s}^{-1}$ [Tan et al., 1998].

\section{Photochemical Recovery of Ozone}

The photochemical calculations presented here have been performed with the chemistry module of the Chemical Lagrangian Model of the Stratosphere (CLaMS) (D. S. McKenna et al., A new Chemical Lagrangian Model of the Stratosphere (ClaMS), Part II: Formulation of Chemistry-Scheme and Initialization, manuscript in preparation, 1999). It utilizes the ASAD software package for atmospheric chemistry modeling [Carver et al., 1997] with the family concept solver IMPACT [Carver and Scott, 1999]. The photolysis rates are calculated by an improved version of the scheme developed by Lary and Pyle [1991] that uses spherical geometry. The heterogeneous reaction rates and the microphysics of liquid ternary $\mathrm{H}_{2} \mathrm{O} / \mathrm{H}_{2} \mathrm{SO}_{4} / \mathrm{HNO}_{3}$ and solid aerosol are calculated using a scheme developed by Carslaw et al. [1995]. Heterogeneous reactions involving bromine compounds are included. The code contains the possibility for the formation of solid particles, but for the time of year considered in this study, the temperatures were high such that only liquid aerosol is important.

The model contains full chlorine and bromine chemistry, 36 chemical species, and 112 reactions (including 24 photolysis and 11 heterogeneous reactions). The reaction rates are obtained from DeMore et al. [1997]. The chemical families are $\mathrm{O}_{X}\left(=\mathrm{O}_{3}+\right.$ $\left.\mathrm{O}\left({ }^{\mathrm{l}} \mathrm{D}\right)+\mathrm{O}\left({ }^{3} \mathrm{P}\right)\right), \mathrm{NO}_{X}\left(=\mathrm{NO}+\mathrm{NO}_{2}+\mathrm{NO}_{3}\right), \mathrm{ClO}_{X}(=\mathrm{Cl}+\mathrm{ClO}+$ $\left.2 \mathrm{Cl}_{2} \mathrm{O}_{2}\right)$, and $\mathrm{BrO}_{X}(=\mathrm{Br}+\mathrm{BrO})$. The time step for the chemistry integration is $10 \mathrm{~min}$, whereas photolysis and heterogeneous reaction rates are calculated every hour. The interaction between the air parcels (e.g., mixing) is not included here.

The recovery of ozone was determined by a pair of similar model integrations, in which only the $\mathrm{O}_{3}$ initialization is different (using both observed and undepleted ozone). Further, the model calculations are initialized with $\mathrm{NO}, \mathrm{NO}_{2}, \mathrm{H}_{2} \mathrm{O}, \mathrm{CH}_{4}$, and $\mathrm{HCl}$ from the mean of 13 measurements from the Halogen Occultation Experiment (HALOE) [Russell et al., 1993] inside the polar vortex in early April 1997. The other species are initialized from the Mainz photochemical 2-D model [Gidel et al., 1983; Grooß, 1996] with a correction for the diabatic descent: The 2-D model altitude level was chosen such that modeled $\mathrm{CH}_{4}$ mixing ratios corresponded to the measured HALOE $\mathrm{CH}_{4}$ mixing ratio. For the photolysis calculation, ozone outside the $350-550 \mathrm{~K}$ region is also given by the HALOE data set mentioned above.

Owing to constraints on computer resources, the box model was run along forward trajectories starting on an equal-area grid with $4^{\circ}$ latitudinal spacing. The calculations were done on the same isentropic levels as before. The ozone depletion (in kilograms) representative of each trajectory was assigned initially on April 11 because the vertical integration in equation (1) was not possible later on. Despite the crude calculations the derived midlatitude dilution is close to the one obtained with the RDF calculations described previously.

Figure 2 also shows that the impact of photochemical ozone recovery on the 1997 dilution is modest. The average midlatitude recovery in May is $12 \%$ of the dilution. By May 30 it amounts to $18 \%$, so it becomes increasingly important to include the reco- very. The sensitivity of the photochemical calculations to the $\mathrm{O}_{3}$ profile used in the photolysis calculation was tested in a separate calculation in which latitude-dependent ozone data from the Mainz 2-D model were used. This was done because the vortex remnants gradually lose their vertical vortex characteristics, and it led to a decrease of the average midlatitude recovery by $0.8 \%$ of the dilution (and a relatively larger increase in the tropics). In 1995 the earlier breakup of the vortex would lead to a larger recovery for May, but the lower height of the dilution would work in the opposite direction.

Since the photochemical recovery depends nonlinearly on the ozone mixing ratios, the combined effect of mixing and recovery could be different from the sum of each effect individually. However, the impact is probably limited.

\section{Conclusion}

The dilution after the PSC-induced vortex ozone depletion period is studied in spring 1995 and 1997, where height-resolved vortex-averaged ozone depletions have been quantified. It was found that the May dilution is about $40 \%$ of the observed depletion for 1979 to 1997 calculated from TOMS trends [WMO, 1999]. The dilution before the PSC-induced depletion stops is usually small because the transport out of the vortex is not much greater than 50\% of the vortex area [McIntyre, 1995; Waugh et al., 1994]. With the crude assumptions that the rate of transport out of the vortex and the vortex depletion rate are constant during winter, a transport of $50 \%$ of the vortex area amounts to a dilution of $25 \%$ of the total depletion inside the vortex when the depletion stops. While this argument might not hold for the winter 1992/1993, where the area of the vortex decreased substantially before the ozone depletion stopped, it seems on firmer ground for the two winters investigated here.

The effect of export of chemically activated air out of the vortex is also small, as seen from the following arguments: The exported air will only deplete the air outside the vortex for, say, 10 days. However, the air inside the vortex stays activated for about 60 days on average in the two winters studied here [Rex et al., 1999; Knudsen et al., 1998b]. Since the exported air constitutes less than about $50 \%$ of the vortex area, the exported air only has a depletion potential of less than about $1 / 12$ of that of the vortex air. These considerations are not in disagreement with the larger chemical activation outside the vortex found by Norton and Chipperfield [1995], because they include PSC processing outside the vortex, which can be substantial. Thus the dilution in spring 1995 and 1997 after the ozone depletion period is likely to contribute more than about $2 / 3$ of the midlatitude depletion due to the vortex. In addition, any midlatitude depletion during winter is subject to photochemical recovery, which decreases its influence on the depletion in spring.

The type of calculations used here (regridded successive highresolution RDF calculations with an attached photochemical box model) could be a powerful tool for a variety of problems. It is a computationally very cheap way of obtaining a nearly realistic treatment of mixing (a horizontal diffusivity of $1.65 \times 10^{3} \mathrm{~m}^{2} \mathrm{~s}^{-1}$ on average).

Acknowledgments. We thank Alain Hauchecorne and Martyn Chipperfield for helpful discussions, and Florence Goutail for providing results prior to publication. Peter von der Gathen at AWI-Potsdam is thanked for providing ozonesonde data. Jean-Jaqcues Morcrette and ECMWF is acknowledged for allowing us to use their radiation scheme and analyses. The Commission for Scientific Research in Greenland, the Danish Research Councils, and DG XII of the Commission of the European Union have supported this work. 


\section{References}

Balluch, M.G., and P.H Haynes, Quantification of lower stratosphenc mixing processes using aircraft data, $J$ Geophys Res., 102, 23,48723,504, 1997.

Becker, G., R. Müller, D.S. McKenna, M. Rex, and K.S. Carslaw, Ozone loss rates in the Arctic stratosphere in the winter 1991/92: Model calculation compared with Match results, Geophys Res Lett, 25, 4325$4328,1998$.

Carslaw, K.S., B.P Luo, and T. Peter, An analytical expression for the composition of aqueous $\mathrm{HNO}_{3}-\mathrm{H}_{2} \mathrm{SO}_{4}-\mathrm{H}_{2} \mathrm{O}$ stratospheric aerosols including gas phase removal of $\mathrm{HNO}_{3}$, Geophys Res Lett, 22, 1877 $1880,1995$.

Carver, G.D., and PA. Scott, IMPACT: An Implicit time integration scheme for chemical species and families, Ann Geophystcae, in press, 1999.

Carver, G.D , P.D. Brown, and O. Wild, The ASAD atmospheric chemistry integration package and chemical reaction database, Comput Phys Commun, 105, 197-215, 1997.

Chıu, E.W , M.P McCormick, and W.P. Chu, Global water vapor distributions in the stratosphere and upper troposphere derived from 5.5 years of SAGE II observations (1986-1991), J Geophys Res, I02, 19,105-19,118, 1997.

Chipperfield, M.P, Multiannual simulations with a three-dimensional chemical transport model, $J$ Geophys Res., 104, 1781-1806, 1999.

DeMore, W.B., et al., Chemical kinetics and photochemical data for use in stratospheric modeling, $J P L$ Publ 97-4, 266pp., Jet Propul Lab, Pasadena, Calif, 1997.

Gidel, L.T , P.J. Crutzen, and J. Fishman, A two-dımensional photochemical model of the atmosphere; 1: Chlorocarbon emissions and their effect on stratospheric ozone, J. Geophys Res., 88, 6622-6640, 1983

Goutail, F., et al, Total ozone reduction in the Arctic vortex during the winters of 1995/96 and 1996/97, Proc. 4th European Symp on Polar Ozone, Air Pollution Research Report 66, Harris, Kilbane-Dawe, and Amanatidis, (ed ), 277-280, European Commission, 1998.

Goutail, F., et al., Total ozone depletion in the Arctic during the winters of 1993/94 and 1994/95, J. Almos Chem, 32, 1-34, 1999.

Grooß, J.-U, Modelling of stratospheric chemistry based on HALOE/UARS satellite data, Ph,D. thesis, Unıversity of Maunz, Germany, 1996

Keating, G.M., M.C. Pitts, and D.F. Young, Ozone reference models for the middle atmosphere, Adv Space Res, 10,317-355, 1990.

Knudsen, B M., W. A Lahoz, A. O'Neill, and J -J. Morcrette, Evidence for a substantral role for dilution in northern mid-latitude ozone depletion, Geophys Res Lett., 25, 4501-4504, 1998a

Knudsen, B. M., et al., Ozone depletion in and below the Arctıc vortex for 1997, Geophys Res. Lett., 25, 627-630, 1998b

Lary, D.J , and J A. Pyle, Diffusive radiation, twilight and photochemistry, $J$ Atmos Chem , 13, 373-406, 1991.
McIntyre, M. E., The stratospheric polar vortex and sub-vortex: Hluid dynamics and mid-latitude ozone loss, Philos Trans $R$ Soc London, Ser A. 352, 227-240, 1995

Morcrette, $\mathrm{J}-\mathrm{J}$., Radiation and cloud radiative properties in the ECMWF operational weather forecast model, J Geophys Res , 96, 9121-9132, 1991.

Norton, W A., and M.P. Chipperfield, Quantification of the transport of chemically activated air from the northern hemisphere polar vortex, $J$ Geophys Res, 100, 25,817-25,840, 1995.

Olaguer, E.P , H. Yang, and $\mathrm{K} \mathrm{K}$ Tung, A reexamination of the radiative balance of the stratosphere, J. Almos Sci. 49, 1242-1263, 1992.

Prather, M.J, Numencal advection by conservation of second-order moments, J Geophys. Res, 91, 6671-6681, 1986.

Prather, M., M.M. Garcia, R. Suozzo, and D Rind, Global impact of the Antarctic ozone hole: dynamical dilution with a three-dimensional chemical transport model, $J$ Geophys Res, 95, 3449-3471, 1990

Rex, M, et al., Chemical ozone loss in the Arctic winter 1994/95 as determined by the Match technique, $J$ Atmos Chem., 32, 35-99, 1999

Russell, J.M , III, L.L. Gordley, J.H. Park, S.R. Drayson, W.D. Hesketh, R.J Cicerone, A.F Tuck, JE Fredenck, JE Harmes, and PJ. Crutzen, The Halogen Occultation Expenment, $J$ Geophys Res , 98, 10,777-10,797, 1993.

Solomon, S, R.W. Portman, R.R. Garcia, L.W Thomason, L R Poole, and M.P. McCormick The role of aerosol variations in anthropogenic ozone depletion at northern midlatitudes, $J$ Geophys Res, I0I, 67136727, 1996.

Tan, D.G.H., P.H. Haynes, A R MacKenzie, and J.A. Pyle, Effects of fluid-dynamical stirring and mixing on the deactivation of stratospheric chlorine, J Geophys. Res, 103, 1585-1606, 1998.

Waugh, D.W , R A Plumb, R.J. Atkinson, M.R Schoeberl, L.R. Lait, PA Newman, M. Loewenstein, D.W. Toohey, L.M. Avallone, C.R. Webster, and R D. May, Transport out of the lower stratospheric Arctic vortex by Rossby wave breaking, $J$ Geophys Res, 99, 1071$1088,1994$.

Waugh, D.W., et al., Mixing of polar vortex alr into middle latıtudes as revealed by tracer-tracer scatterplots, $J$ Geophys Res, 102, 13,11913,134, 1997.

World Meteorological Organization (WMO), Scıentific assessment of ozone depletion 1998, Global Ozone Res Monttor Proj Rep 44, Geneva, 1999

J.-U. Grooß, Forschungszentrum Jülıch, Institute for Stratospheric Chemıstry (ICG-1), 52425 Jülich, Germany. (j-u grooss@fz-juelich de)

B M. Knudsen, Danish Meteorological Institute, Division of Middle Atmosphere Research, Lyngbyvej 100, 2100 Copenhagen, Denmark. (bk@dmi.dk)

(Recerved June 29, 1999; revised September 8, 1999; accepted October 19, 1999.) 